\title{
Public Awareness and Knowledge of Herpes Labialis
}

\author{
Francesca Pica ${ }^{1}$ and Antonio Volpi ${ }^{2 *}$ \\ ${ }^{1}$ Department of Experimental Medicine, University of Rome "Tor Vergata", Rome, Italy \\ ${ }^{2}$ Department of Public Health, University of Rome "Tor Vergata", Rome, Italy
}

Between $20 \%$ and $40 \%$ of the population is estimated to suffer from episodes of recurrent herpes labialis, although few reports in the literature have addressed the public awareness of this infection in the general population. The aims of this study were to determine the existing level of awareness and knowledge of this disease and to assess the source of this knowledge, the ability of the public to recognize the characteristics of the disease and the behavior of patients with clinical cases of disease manifestation. To this end, 2,000 individuals (961 male and 1,039 female) of 14 years of age and older were surveyed using the ECOcapi system [Eurisko Consumer Omnibus-CAPI (computer-assisted personal interviewing) version]. Eighty-nine percent of those surveyed had some knowledge of herpes labialis; $92 \%$ were able to refer to at least one symptom of herpes labialis, $91 \%$ were able to identify correctly his infection from pictures, and $45 \%$ had experienced personally at least one episode of herpes labialis infection. The majority of the individuals suffering from herpes labialis self-medicated using a topical therapy. Women were found to be affected more commonly by herpes labialis than men [OR 1.42 (1.18-1.70)], and women were also more likely to recognize the disease [OR $1.65(1.30-2.08)]$ and to seek medical advice for the condition [OR $1.38(1.12-1.70)$ ]. In conclusion, herpes labialis is a common and wellknown condition, and it is often self-diagnosed correctly, as the prodromal phase and the use of self-medication are very common. J. Med. Virol. 9999:1-6, 2011. () 2011 Wiley-Liss, Inc.

KEY WORDS: herpes simplex virus; herpes labialis; public awareness; public health; epidemiology

\section{INTRODUCTION}

Herpes simplex virus (HSV) infection is responsible for a wide array of human diseases that range from mild, localized HSV infection in the general population to severe life-threatening infections in immunocompromized individuals. HSV-type 1 (HSV-1) infection is usually acquired during childhood and adolescence, and symptomatic infections are characterized by oral or facial lesions [Whitley et al., 2007]. Although HSV-1 is transmitted most often by nonsexual contact, data from certain developed countries indicate that an increasing proportion of first-episode genital herpes infections are caused by HSV-1, and this is the major pattern of infection in many areas [Smith and Robinson, 2002]. The seroprevalence of HSV-1 varies considerably, but it has been shown to increase with age, as $88 \%$ of individuals are seropositive at the age of 40 years and older [Wutzler et al., 2000].

Recurrent infections with herpes labialis, also known as "cold sores" or "fever blisters," are the most common manifestation of oral HSV-1 infection. Between $20 \%$ and $40 \%$ of the general population are estimated to suffer from herpes labialis [Higgins et al., 1993]. Given the high prevalence of HSV-1 infection, the susceptibility to HSV recurrence accounts for only a minor fraction of infected individuals. Additional factors that influence infection include the expression of genetic markers, epidermal cell susceptibility, the relative potency of different HSV strains and differences in the type and/or strength of antiviral immunity and interferon response [Kohl, 1992; Spruance et al., 1995; Casrouge et al., 2006; Seppanen et al., 2006; Kittan et al., 2007; Whitley et al., 2007; Paladino and Mossman, 2009; Pica et al., 2010].

\footnotetext{
Grant sponsor: GlaxoSmithKline Consumer Healthcare S.p.A. Disclosure: AV received an honorarium as a speaker and served as an advisor to GSK, Novartis, and Menarini.

*Correspondence to: Antonio Volpi, MD, Malattie Infettive, Dipartimento di Sanità Pubblica, Università di Roma "Tor Vergata", Via Montpellier 1, 00133 Roma, Italy.

E-mail: volpi@med.uniroma2.it

Accepted 15 August 2011

DOI 10.1002/jmv.22233

Published online in Wiley Online Library

(wileyonlinelibrary.com).
} 
The effect of herpes labialis infection varies considerably from patient-to-patient; in some, infection is infrequent and considered a minor nuisance, but in others, the infection can become a frequent occurrence which is associated with physical signs and symptoms as well considerable social stigmatization due to its central facial location [Volpi and Stanberry, 2007]. Episodic or prophylactic treatment with antiviral therapy is the current standard of care for herpes labialis [Gilbert et al., 2007].

Herpes labialis is a clinical condition that has been known for centuries. The prevalence of this infection throughout history is documented in the following line delivered by Mercutio in Act I, scene IV of Romeo and Juliet: “O'er ladies' lips, who straight on kisses dream, Which oft the angry Mab with blisters plagues" [Shakespeare, 1599]. However, few recent reports in the literature have addressed the public awareness of this infection [Axel and Liedholm, 1990; Lamey and Biagioni, 1996; Gallais et al., 2000; Lowhagen et al., 2002]. Furthermore, there have been few recent studies that have focused on the prevalence of symptomatic herpes labialis in selected countries [Kleinman et al., 1994; Cowan et al., 1996; Lamey and Biagioni, 1996; Gallais et al., 2000].

Due to the absence of objective data in the literature concerning the public knowledge of herpes labialis, this large investigation examined the existing level of public awareness and knowledge of this infection in Italy and assessed the source of this knowledge, the ability to recognize accurately the infection and the behavior of patients with clinical manifestations.

\section{METHODS}

The Herpes Labialis Awareness Survey was conducted between June 7 and June 17, 2005 in Italy. A questionnaire was designed which was administered by GfK Eurisko (http://www.gfk.com/gfk-eurisko/), a firm that provides information services and analyses in several fields including that of health care.

The survey was conducted using the ECOcapi system [Eurisko Consumer Omnibus, CAPI (computerassisted personal interviewing) version]. This system consisted of face-to-face interviews performed with the aid of a laptop computer to show the questionnaire as well as the pictures and video applications.

The questionnaire consisted of seven multiplechoice questions (one closed-ended and six open-ended) that addressed the following three broad themes: the knowledge, symptoms and treatment of herpes labialis (Fig. 1). The term "herpes labialis" and the local term "febbre del labbro" (cold sores) were used in the interviews. The answers provided by the interviewees were entered immediately into the survey by the interviewer for quality control and expedient data processing. The data were processed by the Eurisko Centro Elaborazione Dati and were expressed as percentages of the total sample.
A total of 2,000 individuals of 14 years of age and older, who were selected at random from different regions of Italy, were enrolled in the study and characterized by age, gender, profession, geographic distribution, and highest level of education. The participants were informed of the aim of the survey, and each participant provided informed consent for the interview. According to Italian regulations, research involving the use of educational tests, survey procedures, interview procedures or the observation of public behavior is exempt from the requirement for approval by an ethical committee.

\section{RESULTS}

Of the 2,000 individuals enrolled in the study, 961 were male and 1,039 female, and all the individuals were white Caucasian Italians. The sample population studied was representative of the Italian population in terms of age, gender, geographic distribution, educational level, and occupation. The demographic characteristics of the individuals surveyed are shown in Table I.

Eighty-nine percent of the individuals surveyed (1,781 out of 2,000 individuals) were found to possess some knowledge of herpes labialis. However, the degree of the knowledge possessed was not consistent among individuals of all ages; individuals under 17 years of age and over 64 years of age were found to have a lower degree of knowledge (84\% and $86 \%$, respectively), and the degree of knowledge was highest $(92 \%)$ in adults between 35 and 45 years of age (data not shown).

Seventy-two percent of those who had knowledge of herpes labialis had acquired it from parents/relatives or friends/acquaintances. Only $21 \%$ and $7 \%$ of these individuals received this information from a physician or pharmacist, respectively, and this was more common in older people (29\% and $10 \%$, respectively, for individuals over 45 years of age) than younger people $(8 \%$ and $1 \%$, respectively, for individuals aged between 14 and 17 years of age).

Ninety-two percent of the individuals who had some knowledge of herpes labialis were able to name at least one symptom/sign of the disease ("swelling" followed by the occurrence of "blisters" was the most frequently cited symptom/sign), and $91 \%$ of these individuals were able to correctly identify the infection from pictures shown on a computer screen.

Forty percent of the total sample population and $45 \%$ of those who had knowledge of herpes labialis had personally experienced this infection at least once. Of these, $25 \%$ reported to have had a single herpes labialis episode, $33 \%$ reported to have had two or three episodes, and $42 \%$ reported to have had more than three episodes.

Of the individuals who had experienced at least one episode of herpes labialis, the first signs or symptoms identified were swelling (47\%) and itching (51\%), and this indicated a moderate level of public knowledge on 


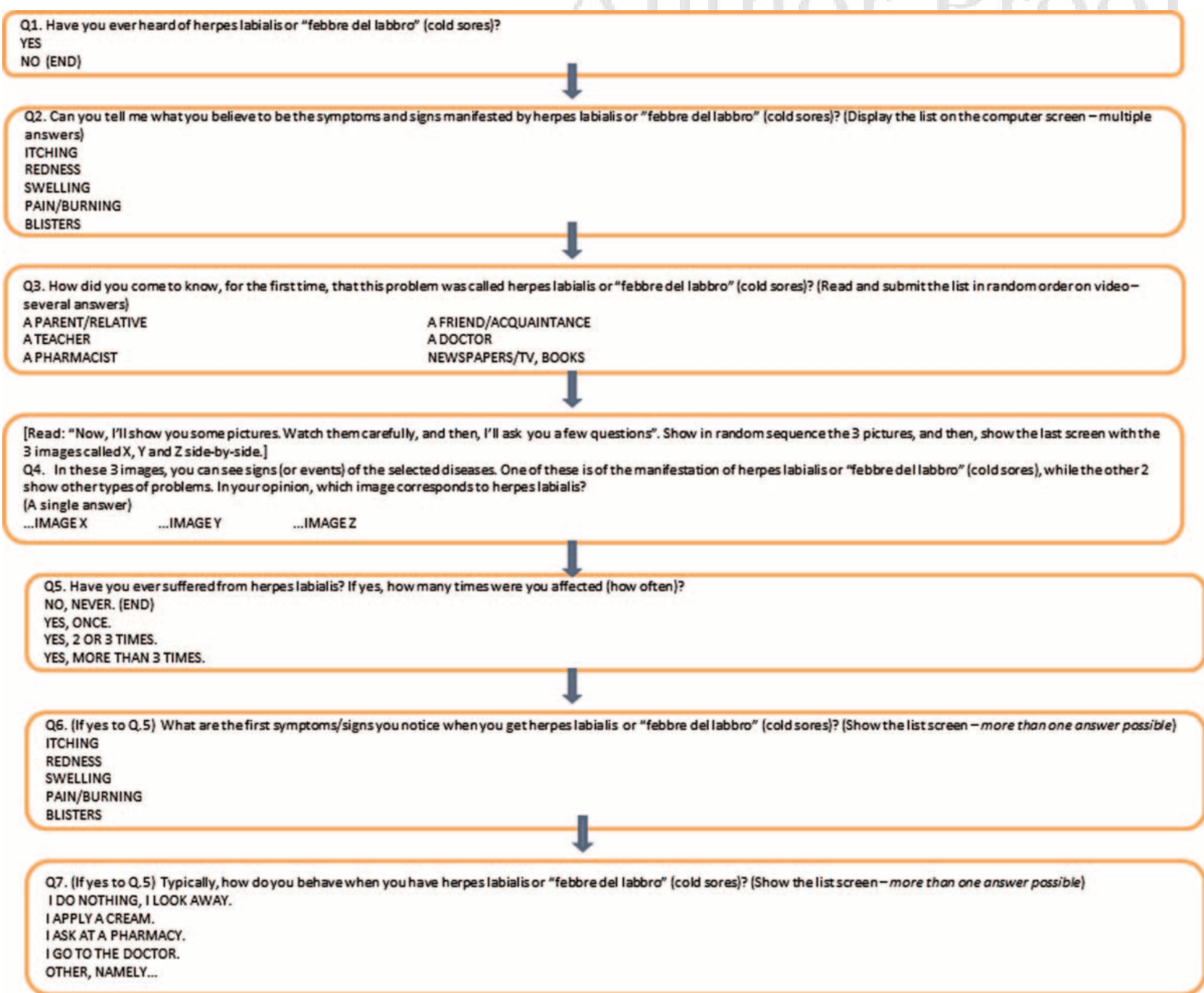

Fig. 1. This flow chart summarizes the sequences of questions and possible answers that determined the respondents' knowledge of herpes labialis infection, the spectrum of symptoms/signs experienced, the frequency of herpes labialis episodes, and the different behaviors and types of treatments received.

the prodromes of herpes labialis. An illustration of the percentages of people surveyed from the general population who had knowledge of, recognized or suffered from herpes labialis infections is shown in Figure 2.

Eighty-one percent of those who had experienced at least one episode of herpes labialis (654 out of 807 individuals) reported at least one behavioral response, and the remaining individuals did not. Among those who responded to their infection, 496 (61.4\%) selfmedicated using a topical cream, 78 (9.7\%) sought medical advice, $91(12.2 \%)$ asked for the advice of a pharmacist and the remainder used various natural products. Interestingly, the frequency of using a cream was the same for those who sought medical advice and those who did not $(65.9 \%$ and $59.7 \%$, respectively).

Finally, herpes labialis infection was more frequently reported by females than males $[44 \%$ vs. $36 \%$, respectively; OR 1.42 (1.18-1.70)], and women were also more likely than men to recognize the disease [91\% vs. $86 \%$, respectively; OR 1.65 (1.30-2.08)], to recognize the disease from pictures $(85 \%$ vs. $77 \%)$ and to implement at least one behavior in response to infection with herpes labialis [83\% vs. $78.5 \%$, respectively; OR 1.38 (1.12-1.70)].

\section{DISCUSSION}

The results of the present study demonstrate that herpes labialis is a well-known disease. The respondents in the survey consistently demonstrated a significant level of knowledge about the characteristic signs and symptoms of herpes labialis (92\% of these individuals cited the presence of swelling and typical vesicles) and were able to recognize and differentiate herpes labialis infection from other pathological 
TABLE I. The Distribution of the Sample Population According to Age, Gender, Geographic Area, Educational Level and Occupation

\begin{tabular}{lcc}
\hline & Males, & Females, \\
& No. $(\%)$ & No. $(\%)$ \\
\hline Age & & \\
14-24 & $142(14.8)$ & $136(13.1)$ \\
$25-34$ & $180(18.7)$ & $176(16.9)$ \\
$35-44$ & $178(18.6)$ & $176(17.0)$ \\
$45-54$ & $152(15.8)$ & $155(14.9)$ \\
$55-64$ & $132(13.8)$ & $142(13.7)$ \\
T64 & $177(18.4)$ & $254(24.4)$ \\
Total & $961(100)$ & $1,039(100)$ \\
Geographic area & & \\
North West & $282(29.4)$ & $251(24.2)$ \\
North East & $161(16.7)$ & $217(20.9)$ \\
Centre & $181(18.8)$ & $209(20.1)$ \\
South and Islands & $337(35.1)$ & $362(34.8)$ \\
Years of education & & \\
Primary & $216(22.4)$ & $343(33)$ \\
Secondary & $398(41.4)$ & $380(36.6)$ \\
High school & $276(28.7)$ & $250(24)$ \\
University Degree & $72(7.5)$ & $66(6.4)$ \\
Occupation & & \\
Professional position & $579(60.2)$ & $321(30.9)$ \\
$\quad$ Entrepreneur/freelance & $176(18.3)$ & $74(7.1)$ \\
professions & & \\
Officer/employee/teacher & $183(19)$ & $163(15.7)$ \\
$\quad$ Worker & $221(23)$ & $84(9.1)$ \\
Position not professional & $382(39.8)$ & $718(69.1)$ \\
$\quad$ Housewife & & $345(33.2)$ \\
Student & $85(8.8)$ & $88(8.5)$ \\
Retired & $217(22.6)$ & $213(20.5)$ \\
$\quad$ Unemployed & $80(8.4)$ & $71(6-9)$ \\
\hline & & \\
\hline & &
\end{tabular}

conditions such as angular cheilitis or perioral acne. As expected, the exclusion of the youngest and oldest individuals from the sample population analyzed resulted in an increase in the percentage of subjects who knew of and could correctly recognize herpes labialis infection. These results obtained for Italian people are in alignment with those reported from studies in

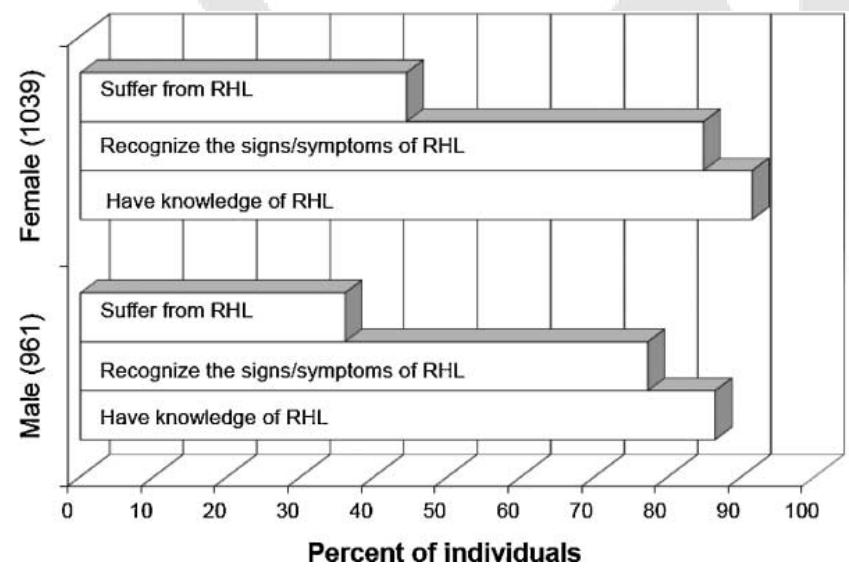

Fig. 2. The relative percentages of people in the studied sample population who demonstrated knowledge of, suffered from or recognized recurrent herpes labialis (RHL) infections. other European countries [Axel and Liedholm, 1990; Kleinman et al., 1994; Cowan et al., 1996; Lamey and Biagioni, 1996; Gallais et al., 2000; Lowhagen et al., 2002].

It is likely that both the high prevalence of HSV-1 infection in the general population and the typical clinical manifestation of herpes labialis enable individuals to know/recognize this infection following the first episode. In the majority of cases, the clinical outbreaks of herpes labialis are commonly preceded by a series of local prodromes, such as pain, tingling, burning, or itching, which are promptly noted and memorized subsequently by the subjects.

Thus, the likelihood that herpes labialis would be confused with other clinical conditions, such as acne, pimples, warts, insect bites, or impetigo, seems rather remote. However, a delayed diagnosis would be of little harm to the patient. In the present study, the possible risk of an over-diagnosis of herpes labialis was avoided by supplying the participants with informative descriptions (both in written text and pictures) on a computer screen during the face-to-face interviews, and this may have increased the validity of the correct diagnosis.

The second significant result of the present study was the finding that the majority of individuals obtained their knowledge of herpes labialis from parents/relatives and friends/acquaintances, and only a minority of the individuals obtained this information from a physician. Indeed, this is a characteristic feature of many ancient and widespread diseases in the world.

In the present study, $40 \%$ of the individuals surveyed had experienced at least one episode of herpes labialis. This percentage is very similar to that reported recently by a French study (39.9\%) [Gallais et al., 2000], but is significantly greater than that found in Sweden (26.6\%) [Lowhagen et al., 2002].

Large inter-country differences in the seroepidemiology of HSV-1 have been documented around the world [Nahmias et al., 1990]. In Europe, the risk for the acquisition of HSV-1 infection has been linked to socio-demographic status, and a north-south/east gradient has been demonstrated for this phenomenon [Pebody et al., 2004]. Furthermore, an inverse correlation between the age-standardized seroprevalence of HSV-1 and the national gross domestic product (correlation $=20.93$ ) has been reported. A large proportion of adolescents remain susceptible to HSV-1 infection in northern Europe, which suggests that the age-dependent force (or risk) of infection for HSV-1 is greater in Southern and Eastern Europe than in Northern Europe. These differences in the epidemiology of HSV-1 have likely occurred only recently [Vyse et al., 2000] and may reflect changes in socioeconomic status and family size [Pebody et al., 2004].

A trend towards an increasing percentage of individuals who have experienced at least one episode of herpes labialis infection was found for those individuals in their middle ages of life (data not shown), which 
is in line with previous observations [Higgins et al., 1993; Wutzler et al., 2000; Smith and Robinson, 2002]. This finding highlights the role of the horizontal spread of the virus among individuals. It has been shown that both primary and recurrent infections result in significant reservoirs of virus that have the potential for transmission to oral and genital sites during periods of intimate contact with other individuals. Symptomatic infections pose the greatest risk for transmission, but the risk of transmission persists during periods of asymptomatic virus shedding [Sacks et al., 2004; Volpi and Stanberry, 2007]. As discussed above, orogenital transmission is a major route for genital HSV-1 infection [Sacks et al., 2004], and for this reason, a greater awareness of the possible risks for the transmission of herpes labialis during an active episode should be promoted among people.

According to the results described above, herpes labialis infection is more common in females than in males. Similar gender differences for clinical disease as well as for estimations of seroprevalence have been reported by other studies [Axel and Liedholm, 1990; Nahmias et al., 1990; Kleinman et al., 1994; Cowan et al., 1996; Vyse et al., 2000; Lowhagen et al., 2002; Pebody et al., 2004].

Finally, the observation that the behavior of Italian and French persons in regards to herpes labialis infection are similar both in terms of the percentages of individuals who seek medical advice $(9.7 \%$ and $7.5 \%$, respectively) and those who use self-medication (61.4\% and 62.9\%, respectively) [Gallais et al., 2000].

On the basis of the present investigation and in line with published reports, it is concluded that herpes labialis is a very frequent infection with a well-known pathology. The clinical manifestations of this disease are usually self-diagnosed correctly by the patients even during the prodromal phase, which is very relevant to antiviral therapy because this treatment is recommended to be initiated in the prodromal phase [Gilbert et al., 2007].

According to the data presented above, physicians are not consulted frequently by individuals affected by herpes labialis, and the use of self-medication is very frequent among adults who are active professionally but is less frequent among older individuals. Furthermore, the tendency to seek medical advice increases only in cases with particularly severe clinical manifestations.

However, the burden of herpes labialis is often underestimated by physicians and regulatory authorities. As an example, in Italy, the use of antiviral drugs for the episodic and suppressive treatment of genital herpes is funded by the national health service; however, this treatment does not cover infections with herpes labialis. This policy is common in other parts of the world as well, and it places severe limitations on the wellbeing of patients [Volpi and Stanberry, 2007].

The ability of the people to self-administer appropriate treatments for herpes labialis infections appears to be confirmed. It is therefore conceivable to hypothesize that an increased availability of over-the-counter systemic and topical antiviral drugs would aid in the correct self-medication of the general population in the absence of any significant risks to public health.

\section{REFERENCES}

Axel T, Liedholm R. 1990. Occurrence of recurrent herpes labialis in an adult Swedish population. Acta Odontol Scand 48:119-123.

Casrouge A, Zhang SY, Eidenschenk C, Jouanguy E, Puel A, Yang K, Alcais A, Picard C, Mahfoufi N, Nicolas N, Lorenzo L, Plancoulaine S, Sénéchal B, Geissmann F, Tabeta K, Hoebe K, Du X, Miller RL, Héron B, Mignot C, de Villemeur TB, Lebon P, Dulac O, Rozenberg F, Beutler B, Tardieu M, Abel L, Casanova JL. 2006. Herpes simplex encephalitis in human UNC-93B deficiency. Science 314:308-312.

Cowan FM, Johnson AM, Ashley R, Corey L, Mindel A. 1996. Relationship between antibodies to herpes simplex virus (HSV) and symptoms of HSV infection. J Infect Dis 174:470-475.

Gallais J, Boisnault P, Morel F, Clerc P, Letrillard L, Hebbrecht G. 2000. Herpes labialis and genitalis in general medicine. Ann Dermatol Venereol 127:596-602.

Gilbert S, Corey L, Cunningham A, Malkin JE, Stanberry L, Whitley R, Spruance S. 2007. An update on short-course intermittent and prevention therapies for herpes labialis. Herpes 14:13A-18A.

Higgins CR, Schofield JK, Tatnall FM, Leigh IM. 1993. Natural ${ }^{\mathrm{Q} 1}$ history, management and complications of herpes labialis. J Med Virol XX:22-26.

Kittan NA, Bergua A, Haupt S, Donhauser N, Schuster P, Korn K, Harrer T, Schmidt B. 2007. Impaired plasmacytoid dendritic cell innate immune responses in patients with herpes virus-associated acute retinal necrosis. J Immunol 179:4219-4230.

Kleinman DV, Swango PA, Pindborg JJ. 1994. Epidemiology of oral mucosal lesions in United States schoolchildren: 1986-1987. Community Dent Oral Epidemiol 22:243-253.

Kohl S. 1992. The role of antibody in herpes simplex virus infection in humans. Curr Top Microbiol Immunol 179:75-88.

Lamey PJ, Biagioni PA. 1996. Patient recognition of recrudescent herpes labialis: A clinical and virological assessment. J Dent 24:325-327.

Lowhagen GB, Bonde E, Eriksson B, Nordin P, Tunbäck P, Krantz I. 2002. Self-reported herpes labialis in a Swedish population. Scand J Infect Dis 34:664-667.

Nahmias AJ, Lee FK, Beckman-Nahmias S. 1990. Sero-epidemiological and sociological patterns of herpes simplex virus infection in the world. Scand J Infect Dis 69:19-36.

Paladino P, Mossman KL. 2009. Mechanisms employed by herpes simplex virus 1 to inhibit the interferon response. J Interferon Cytokine Res 29:599-607.

Pebody RG, Andrews N, Brown D, Gopal R, De Melker H, François G, Gatcheva N, Hellenbrand W, Jokinen S, Klavs I, Kojouharova M, Kortbeek T, Kriz B, Prosenc K, Roubalova K, Teocharov P Thierfelder W, Valle M, Van Damme P, Vranckx R. 2004. The seroepidemiology of herpes simplex virus type 1 and 2 in Europe. Sex Transm Infect 80:185-191.

Pica F, Volpi A, Gaziano R, Garaci E. 2010. Interferon-lambda in immunocompetent individuals with a history of recurrent herpes labialis. Antivir Ther 15:737-743.

Sacks SL, Griffiths PD, Corey L, Cohen C, Cunningham A, Dusheiko GM, Self S, Spruance S, Stanberry LR, Wald A, Whitley RJ. 2004. HSV shedding. Antiviral Res 63:S19-S26.

Seppanen M, Meri S, Notkola IL, Seppala IJ, Hiltunen-Back E Sarvas H, Lappalainen M, Valimaa H, Palikhe A, Valtonen VV, Lokki ML. 2006. Subtly impaired humoral immunity predispose to frequently recurring genital herpes simplex virus type 2 infection and herpetic neuralgia. J Infect Dis 194:571-578.

Shakespeare W. 1599. Mercutio talk. In "Romeo and Juliet", Act I, scene IV.

Smith JS, Robinson NJ. 2002. Age-specific prevalence of infection with herpes simplex virus types 2 and 1: A global review. J Infect Dis 186:S3-S28.

Spruance LS, Evans TG, McKeough MB. 1995. Th1/th2-like immunity and resistance to herpes simplex labialis. Antiviral Res 28:39-55. 
Volpi A, Stanberry L. 2007. Tailoring herpes labialis treatments. Herpes 14:55.

Vyse AJ, Gay NJ, Slomka MJ, Gopal R, Gibbs T, Morgan-Capner P, Brown DW. 2000. The burden of infection with HSV-1 and HSV 2 in England and Wales: Implications for the changing epidemiology of genital herpes. Sex Transm Infect 76:183-187.

Whitley R, Kimberlin DW, Prober CG. 2007. Pathogenesis and disease. In: Arvin A, Campadelli-Fiume G, Mocarski E, Moore
PS, Roizman B, Whitley R, Yamanishi K, editors. Human herpesviruses: Biology, therapy, and immunoprophylaxis. Cambridge: Cambridge University Press, Chapter 32.

Wutzler P, Doerr HW, Färber I, Eichhorn U, Helbig B, Sauerbrei A, Brandstädt A, Rabenau HF. 2000. Seroprevalence of herpes simplex virus type 1 and type 2 in selected German populations: Relevance for the incidence of genital herpes. J Med Virol 61:201-207.

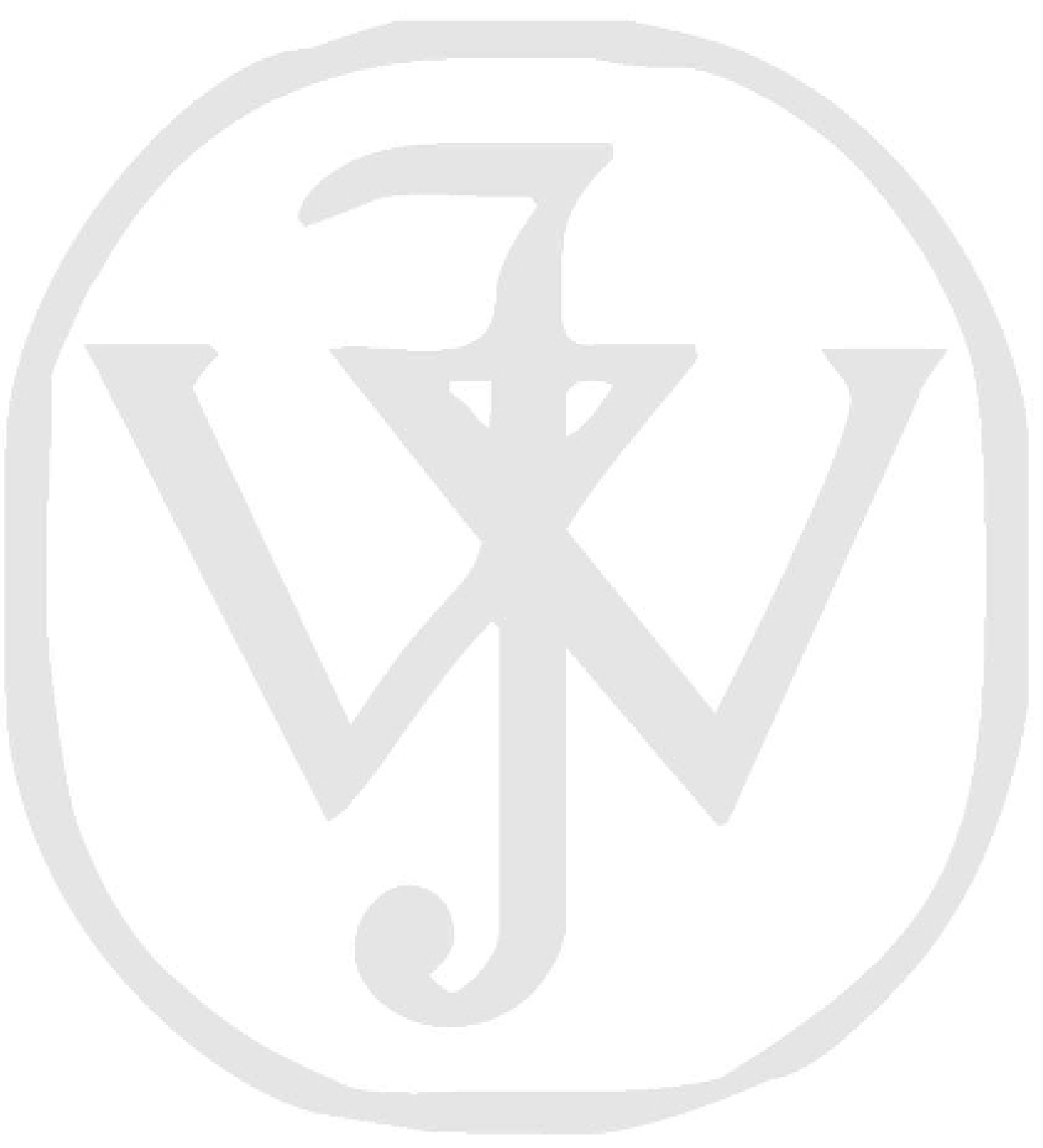




\section{AUTHOR QUERY FORM}

\section{JOURNAL: JOURNAL OF MEDICAL VIROLOGY Article: jmv_22233}

Dear Author,

During the copyediting of your paper, the following queries arose. Please respond to these by annotating your proofs with the necessary changes/additions.

- If you intend to annotate your proof electronically, please refer to the E-annotation guidelines.

- If you intend to annotate your proof by means of hard-copy mark-up, please refer to the proof mark-up symbols guidelines. If manually writing corrections on your proof and returning it as a scanned pdf via email, do not write too close to the edge of the paper. Please remember that illegible mark-ups may delay publication.

Whether you opt for hard-copy or electronic annotation of your proofs, we recommend that you provide additional clarification of answers to queries by entering your answers on the query sheet, in addition to the text mark-up.

\begin{tabular}{|c|l|c|}
\hline Query No. & \multicolumn{1}{|c|}{ Query } & Remark \\
\hline Q1 & $\begin{array}{l}\text { Please provide volume number for the reference Higgins et al., } \\
1993 .\end{array}$ & \\
\hline
\end{tabular}




\section{USING E-ANNOTATION TOOLS FOR ELECTRONIC PROOF CORRECTION}

\section{Required Software}

Adobe Acrobat Professional or Acrobat Reader (version 7.0 or above) is required to e-annotate PDFs. Acrobat 8 Reader is a free download: http://www.adobe.com/products/acrobat/readstep2.html.

For help with system requirements, go to: http://www.adobe.com/support/.

Once you have Acrobat Reader on your PC and open the proof, you will see the Commenting Toolbar (if it does not appear automatically go to Tools>Commenting>Commenting Toolbar). If these options are not available in your Adobe Reader menus then it is possible that your Adobe version is lower than 7 or the PDF has not been prepared properly.

PDF Annotations (Adobe Reader version 7 or 8 ) - Commenting Toolbars look like this:

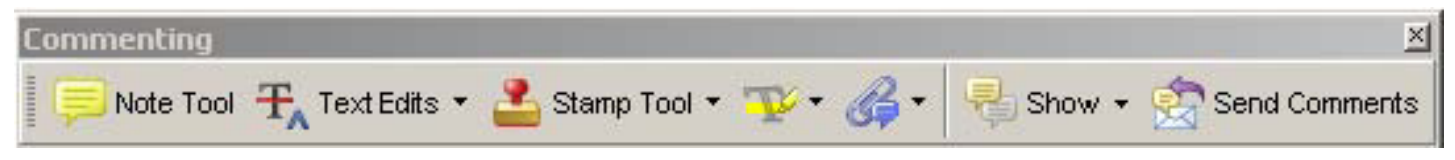

(PC, Adobe version 7)

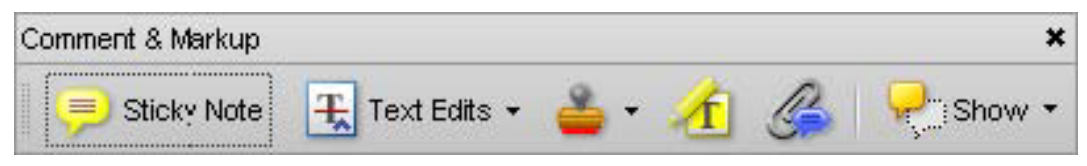

(PC, Adobe version 8, right-click on title bar (Comment \& Markup) to show additional icons)

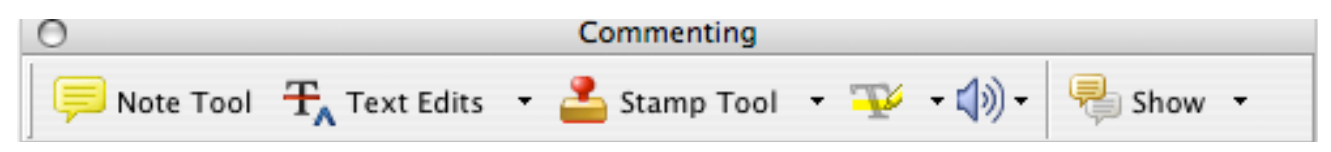

(Mac)

\section{PDF Annotations (Adobe Reader version 9)}

If you experience problems annotating files in Adobe Acrobat Reader 9 then you may need to change a preference setting in order to edit.

The default for the Commenting toolbar is set to 'off' in version 9. To change this setting select 'Edit | Preferences', then 'Documents' (at left under 'Categories'), then select the option 'Never' for 'PDF/A View Mode'. (the Commenting toolbar is the same as in version 8).

PDF/A View Mode

View documents in PDF/A mode: Never 


\section{TO INDICATE INSERT, REPLACE, OR REMOVE TEXT}

- Insert text

Click the 'Text Edits' $\mathbf{F}_{\Lambda}$ Text Edits - button on the Commenting toolbar. Click to set the cursor location in the text and simply start typing. The text will appear in a commenting box. You may also cut-and-paste text from another file into the commenting box. Close the box by clicking on ' $x$ ' in the top right-hand corner. It can be deleted by right clicking (for the PC, ctrl-click on the Mac) on it and selecting 'Delete'.

\section{- Replace text}

Click the 'Text Edits' button on the Commenting toolbar. To highlight the text to be replaced, click and drag the cursor over the text. Then simply type in the replacement text. The replacement text will appear in a commenting box. You may also cut-and-paste text from another file into this box. To replace formatted text (an equation for example) please Attach a file (see below).

\section{- Remove text}

Click the 'Text Edits' button on the Commenting toolbar. Click and drag over the text to be deleted. Then press the delete button on your keyboard. The text to be deleted will then be struck through.

\section{HIGHLIGHT TEXT/MAKE A COMMENT}

Click on the 'Highlight' button on the commenting toolbar. Click and drag over the text. To make a comment, double click on the highlighted text and simply start typing.

\section{ATTACH A FILE}

Click on the 'Attach a file' 3 button on the commenting toolbar. Click on the figure, table or formatted text to be replaced. A window will automatically open allowing you to attach a file. To make a comment, go to 'General' and then 'Description' in the 'Properties' window. A graphic will appear indicating the insertion of a file.

\section{LEAVE A NOTE/COMMENT}

Click on the 'Note Tool' Note Tool button on the commenting toolbar. Click to set the location of the note on the document and simply start typing. Do not use this feature to make text edits.

\section{REVIEW}

To review your changes, click on the 'Show' show - button on the commenting toolbar. Choose 'Show Comments List'. Navigate by clicking on a correction in the list. Alternatively, double click on any mark-up to open the commenting box.

\section{UNDO/DELETE CHANGE}

To undo any changes made, use the right click button on your mouse (for PCs, Ctrl-Click for Mac). Alternatively click on the 'Edit' in the main Adobe menu and then 'Undo'. You can also delete edits using the right click (Ctrl-Click on the Mac) and selecting 'Delete'.

\section{SEND YOUR ANNOTATED PDF FILE BACK TO WILEY VIA jmvprod@wiley.com}

Save the annotations to your file and return as an e-mail. Before returning, please ensure you have answered any questions raised on the Query form that you have inserted all the corrections: later inclusion of any subsequent corrections cannot be guaranteed.

Note: Comprehensive instructions are provided within your PDF file: to access these instructions please click on the Comments and Markup menu in the main tool bar, or click on Help. 
Date:

Contributor name:

Contributor address:

Manuscript number (Editorial office only):

Re: Manuscript entitled

(the "Contribution")

for publication in (the "Journal")

published by ("Wiley-Blackwell").

Dear Contributor(s):

Thank you for submitting your Contribution for publication. In order to expedite the editing and publishing process and enable Wiley-Blackwell to disseminate your Contribution to the fullest extent, we need to have this Copyright Transfer Agreement signed and returned as directed in the Journal's instructions for authors as soon as possible. If the Contribution is not accepted for publication, or if the Contribution is subsequently rejected, this Agreement shall be null and void. Publication cannot proceed without a signed copy of this Agreement.

\section{A. COPYRIGHT}

1. The Contributor assigns to Wiley-Blackwell, during the full term of copyright and any extensions or renewals, all copyright in and to the Contribution, and all rights therein, including but not limited to the right to publish, republish, transmit, sell, distribute and otherwise use the Contribution in whole or in part in electronic and print editions of the Journal and in derivative works throughout the world, in all languages and in all media of expression now known or later developed, and to license or permit others to do so.

2. Reproduction, posting, transmission or other distribution or use of the final Contribution in whole or in part in any medium by the Contributor as permitted by this Agreement requires a citation to the Journal and an appropriate credit to Wiley-Blackwell as Publisher, and/or the Society if applicable, suitable in form and content as follows: (Title of Article, Author, Journal Title and Volume/Issue, Copyright @ [year], copyright owner as specified in the Journal). Links to the final article on Wiley-Blackwell's website are encouraged where appropriate.

\section{B. RETAINED RIGHTS}

Notwithstanding the above, the Contributor or, if applicable, the Contributor's Employer, retains all proprietary rights other than copyright, such as patent rights, in any process, procedure or article of manufacture described in the Contribution

\section{PERMITTED USES BY CONTRIBUTOR}

1. Submitted Version. Wiley-Blackwell licenses back the following rights to the Contributor in the version of the Contribution as originally submitted for publication:

a. After publication of the final article, the right to self-archive on the Contributor's personal website or in the Contributor's institution's/employer's institutional repository or archive. This right extends to both intranets and the Internet. The Contributor may not update the submission version or replace it with the published Contribution. The version posted must contain a legend as follows: This is the pre-peer reviewed version of the following article: FULL CITE, which has been published in final form at [Link to final article].

b. The right to transmit, print and share copies with colleagues.

2. Accepted Version. Re-use of the accepted and peer-reviewed (but not final) version of the Contribution shall be by separate agreement with WileyBlackwell. Wiley-Blackwell has agreements with certain funding agencies governing reuse of this version. The details of those relationships, and other offerings allowing open web use, are set forth at the following website: http://www.wiley.com/go/funderstatement. NIH grantees should check the box at the bottom of this document.
3. Final Published Version. Wiley-Blackwell hereby licenses back to the Contributor the following rights with respect to the final published version of the Contribution:

a. Copies for colleagues. The personal right of the Contributor only to send or transmit individual copies of the final published version in any format to colleagues upon their specific request provided no fee is charged, and further-provided that there is no systematic distribution of the Contribution, e.g. posting on a listserve, website or automated delivery.

b. Re-use in other publications. The right to re-use the final Contribution or parts thereof for any publication authored or edited by the Contributor (excluding journal articles) where such re-used material constitutes less than half of the total material in such publication. In such case, any modifications should be accurately noted.

c. Teaching duties. The right to include the Contribution in teaching or training duties at the Contributor's institution/place of employment including in course packs, e-reserves, presentation at professional conferences, in-house training, or distance learning. The Contribution may not be used in seminars outside of normal teaching obligations (e.g. commercial seminars). Electronic posting of the final published version in connection with teaching/training at the Contributor's institution/place of employment is permitted subject to the implementation of reasonable access control mechanisms, such as user name and password. Posting the final published version on the open Internet is not permitted.

d. Oral presentations. The right to make oral presentations based on the Contribution.

4. Article Abstracts, Figures, Tables, Data Sets, Artwork and Selected Text (up to 250 words).

a. Contributors may re-use unmodified abstracts for any non-commercial purpose. For on-line uses of the abstracts, Wiley-Blackwell encourages but does not require linking back to the final published versions.

b. Contributors may re-use figures, tables, data sets, artwork, and selected text up to 250 words from their Contributions, provided the following conditions are met:

(i) Full and accurate credit must be given to the Contribution.

(ii) Modifications to the figures, tables and data must be noted. Otherwise, no changes may be made.

(iii) The reuse may not be made for direct commercial purposes, or for financial consideration to the Contributor.

(iv) Nothing herein shall permit dual publication in violation of journal ethical practices. 


\section{CONTRIBUTIONS OWNED BY EMPLOYER}

1. If the Contribution was written by the Contributor in the course of the Contributor's employment (as a "work-made-for-hire" in the course of employment), the Contribution is owned by the company/employer which must sign this Agreement (in addition to the Contributor's signature) in the space provided below. In such case, the company/employer hereby assigns to Wiley-Blackwell, during the full term of copyright, all copyright in and to the Contribution for the full term of copyright throughout the world as specified in paragraph A above.

2. In addition to the rights specified as retained in paragraph $B$ above and the rights granted back to the Contributor pursuant to paragraph $C$ above, WileyBlackwell hereby grants back, without charge, to such company/employer, its subsidiaries and divisions, the right to make copies of and distribute the final published Contribution internally in print format or electronically on the Company's internal network. Copies so used may not be resold or distributed externally. However the company/employer may include information and text from the Contribution as part of an information package included with software or other products offered for sale or license or included in patent applications. Posting of the final published Contribution by the institution on a public access website may only be done with Wiley-Blackwell's written permission, and payment of any applicable fee(s). Also, upon payment of Wiley-Blackwell's reprint fee, the institution may distribute print copies of the published Contribution externally.

\section{E. GOVERNMENT CONTRACTS}

In the case of a Contribution prepared under U.S. Government contract or grant, the U.S. Government may reproduce, without charge, all or portions of the Contribution and may authorize others to do so, for official U.S. Govern- ment purposes only, if the U.S. Government contract or grant so requires. (U.S. Government, U.K. Government, and other government employees: see notes at end)

\section{F. COPYRIGHT NOTICE}

The Contributor and the company/employer agree that any and all copies of the final published version of the Contribution or any part thereof distributed or posted by them in print or electronic format as permitted herein will include the notice of copyright as stipulated in the Journal and a full citation to the Journal as published by Wiley-Blackwell.

\section{G. CONTRIBUTOR'S REPRESENTATIONS}

The Contributor represents that the Contribution is the Contributor's original work, all individuals identified as Contributors actually contributed to the Contribution, and all individuals who contributed are included. If the Contribution was prepared jointly, the Contributor agrees to inform the co-Contributors of the terms of this Agreement and to obtain their signature to this Agreement or their written permission to sign on their behalf. The Contribution is submitted only to this Journal and has not been published before. (If excerpts from copyrighted works owned by third parties are included, the Contributor will obtain written permission from the copyright owners for all uses as set forth in WileyBlackwell's permissions form or in the Journal's Instructions for Contributors, and show credit to the sources in the Contribution.) The Contributor also warrants that the Contribution contains no libelous or unlawful statements, does not infringe upon the rights (including without limitation the copyright, patent or trademark rights) or the privacy of others, or contain material or instructions that might cause harm or injury.

\section{CHECK ONE BOX:}

Contributor-owned work ATTACH ADDITIONAL SIGNATURE PAGES AS NECESSARY

Contributor's signature

Date

Type or print name and title

Type or print name and title

Company/Institution-owned work

(made-for-hire in the course of employment) which is an official U.S. Government publication, is called a "U.S. Government work," and is in the public domain in the United States. In such case, the employee may cross out Paragraph A. 1 but must sign (in the Contributor's signature line) and return this Agreement. If the Contribution was not prepared as part of the employee's duties or is not an official U.S. Government publication, it is not a U.S. Government work. U.K. Government work
(Crown Copyright)

\section{Note to U.K. Government Employees}

The rights in a Contribution prepared by an employee of a U.K. government department, agency or other Crown body as part of his/her official duties, or which is an official government publication, belong to the Crown. U.K. government authors should submit a signed declaration form together with this Agreement. The form can be obtained via http://www.opsi.gov.uk/advice/crown-copyright/copyright-guidance/ publication-of-articles-written-by-ministers-and-civil-servants.htm

\footnotetext{
Other Government work
}

If your status as a government employee legally prevents you from signing this Agreement, please contact If your status as a gove
the editorial office. 


\section{COLOR REPRODUCTION IN YOUR ARTICLE}

These proofs have been typeset using figure files transmitted to production when this article was accepted for publication. Please review all figures and note your approval with your submitted proof corrections. In the event that color figure were included with the final manuscript files that we received for your article, this form must be completed and returned with your corrected proofs.

Because of the high cost of color printing, we can only print figures in color if authors cover the expense. Please indicate if you agree to pay charges for color figures to be printed in color (see table below for prices) or prefer black and white reproduction.

You will be invoiced for color charges once the article has been published in print.

Failure to return this form with your article proofs may delay the publication of your article. JOURNAL OF MEDICAL VIROLOGY

JOURNAL MS. NO. NO. COLOR PAGES

MANUSCRIPT TITLE

AUTHOR(S)

\begin{tabular}{|c|c|c|c|c|c|}
\hline No. Color Pages & Color Charge & No. Color Pages & Color Charge & No. Color Pages & Color Charge \\
\hline$\square$ & $\$ 950$ & 5 & $\$ 3400$ & $\square$ & $\$ 5850$ \\
\hline 2 & $\$ 1450$ & $\square$ & $\$ 3900$ & 10 & $\$ 6350$ \\
\hline 3 & $\$ 1950$ & 7 & $\$ 4400$ & 11 & $\$ 6850$ \\
\hline$\square$ & $\$ 2450$ & $\square$ & $\$ 4900$ & 12 & $\$ 7350$ \\
\hline
\end{tabular}

Please print my figures color

Please print my figures in black and white

Please print the following figures in color and convert these figures to black and white

Approved by

Billing Address

E-mail

Telephone

Fax 


\section{(3)WILEY-BLACKWELL}

Additional reprint and journal issue purchases

Should you wish to purchase additional copies of your article, please click on the link and follow the instructions provided: https://caesar.sheridan.com/reprints/redir.php?pub=10089\&acro=JMV

Corresponding authors are invited to inform their co-authors of the reprint options available.

Please note that regardless of the form in which they are acquired, reprints should not be resold, nor further disseminated in electronic form, nor deployed in part or in whole in any marketing, promotional or educational contexts without authorization from Wiley. Permissions requests should be directed to mailto: permissionsus@wiley.com

For information about 'Pay-Per-View and Article Select' click on the following link: http://wileyonlinelibrary.com/ppv 